He also rejects theories that regard content as the fusion of internal and external factors, though far less convincingly. First, he mistakenly assumes that 'twofactor' theories take each factor to determine a unique proposition: but the whole point of such theories is that this is not so. Second, his own earlier notion of narrow content supplies precisely what the twofactor theorist needs to rebut Fodor's criticism. Third, Fodor's reluctance to allow any place for functional role in the fixation of content sits ill with his previous claim that content is conferred by a harmony between inferential propensities and logical consequence.

Naturalism would be a threat if we could not explain mental reference in naturalistic terms. Fodor tries to develop a causal covariation theory of reference, thus explaining where meaning fits in the natural order. This is an ingenious discussion, but problems bristle - in particular, the problem of explaining the possession of content in the absence of appropriate environmental entities. What would he say about the brain in a vat? It looks as if he has to say, implausibly, that the causally isolated terms in its language of thought either have no content or some very bizarre sort of content concerning nerve-endings or some such. I think Fodor should reconsider the prospects for a teleological theory, which he dismisses too quickly. Pure causal theories face formidable problems, especially with respect to the phenomenological content of perceptual experience - a type of content he conspicuously fails to discuss.

Fodor may not have the last word on all issues, as he would be the first to admit. But his forthrightness and intellectual daring are the best way to push our understanding forward. Psychosemantics is a notable contribution to the old question of how the mind represents the world.

Colin McGinn is Wilde Reader in Mental Philosophy at the University of Oxford, and a Fellow of Corpus Christi College, Oxford OXI $4 J F, U K$.

- Daniel Dennett is another philosopher who believes in the value of commonsense psychology. But in The Intentional Stance, a collection of his recent essays also published by MIT Press ( $\$ 25, £ 19.95)$, he parts company with Fodor by arguing that the pattern of commonsense explanation is not necessarily mirrored in a "language of thought" in the brain. Connectionist models might just turn out to provide one alternative, according to Dennett, for neural networks appear to perform cognitive tasks - the correct pronunciation of written English, for example - without any rules being explicitly represented anywhere in the network.

Dennett's “intentional stance" leads him through a rich and varied landscape, from speculations on frog psychology to a critique of adaptionism that should do much to silence those biologists who believe that philosophers never have anything useful to say to them.

An encounter with ethologists provokes two of the most entertaining essays. Dennett sets off for Kenya, with primatologist Robert Seyfarth, to see (tentatively) if light can be shed on the remarkable communication abilities of vervet monkeys by adopting the intentional stance; that is, by using explanatory intentional idioms, such as 'believes' or 'wants'. The result is surprising: Dennett, retaining philosophical rigour, is able to develop indirectly testable hypotheses of what particular monkey calls might mean. But his method leads him also to conclude that vervet monkeys "like honeymooners who have not been out of each other's sight for days" have rather little to say to one another. For a more complex language to be useful, a few more opportunities for deceit are required!

Alun Anderson

\section{Fighting fungi}

\section{G.A. Pepin}

Introduction to the History of Medical and Veterinary Mycology. By G.C. Ainsworth. Cambridge University Press: 1987. Pp.228. £30, \$54.50.

IN ITs popular image, mycology deals with mushrooms, moulds and mildew. This view may extend to the wider range of fungal infections in plants but usually stops short of human or animal disease. Yet, world-wide, millions of people and their livestock are infected by fungi. Many of these infections cause only mild disease but others do not: they disfigure, disable or kill. Moreover, fungal growth in food crops, before or after harvest, sometimes produces potent toxins that cause disease if eaten, and millions of dollars have been spent over recent years in efforts to prevent them entering the diet of animals or human beings.

Despite its title, Dr Ainsworth's book is not solely for historians; anyone interested in the biology of infectious disease should find it stimulating, entertaining and instructive. He traces knowledge of diseases caused by fungi from antiquity to the present day, but points out that by far the greatest progress in medical and veterinary mycology occurred only within the past 50 years. Why did such problems attract so little effective attention for so long? After all, fungal infections were the first to be scientifically proven in the nineteenth century, when the whole notion of disease caused by microbial invasion was new and controversial.

Segregation within science was partly to blame. Once the relative importance of bacteria and, later, viruses in the epi- demic, contagious diseases became apparent, medical attention was focused upon them, and the new sciences of bacteriology and virology developed in close alliance with clinical research. Mycology, on the other hand, remained within the province of botanists, whose interests and experience led them to concentrate upon fungi responsible for plant diseases. Out of their work grew a body of knowledge, methods and skills relevant to medical mycology but rarely applied to it until the 1930 s, when the need

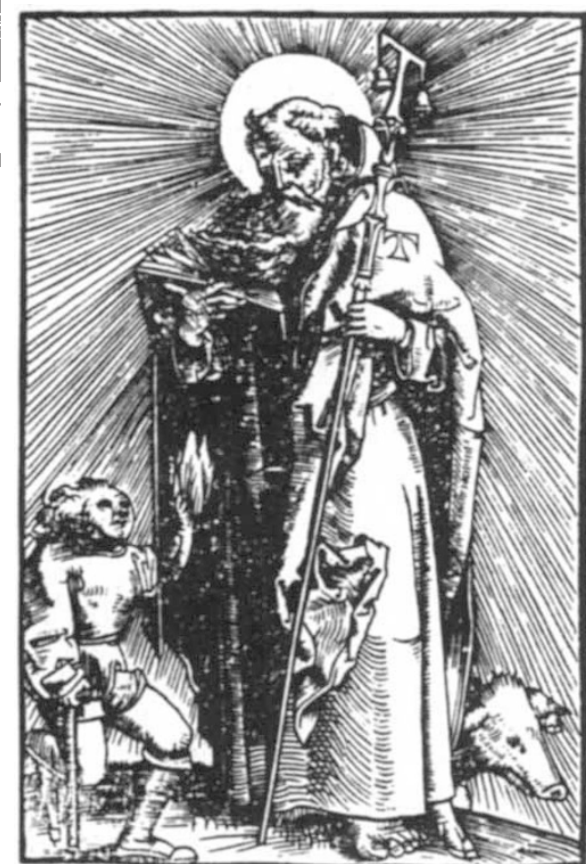

St Antony with a victim of gangrenous ergotism, which can be contracted from the rye used for baking bread ( $H$. von Gersdorff, Feldbuch der Wundartzney, 1551). Courtesy of Geoffrey $C$. Ainsworth.

for clinicians and mycologists to collaborate at last began to be accepted.

Throughout his career Dr Ainsworth has been active in furthering such collaboration and the consequent advance of medical and veterinary mycology. With a wide knowledge of mycology, its applications and history, coupled with a talent for conveying lucidly and succinctly the essence of his subject, he is uniquely able to communicate both the difficulties and the achievements of workers in this field.

More than a history, this short, scholarly book is an up-to-date synopsis of the subject, summarizing both past and present approaches to most of its essential problems and briefly reviewing progress in the various regions of the world. Particularly valuable is the extensive and wellorganized bibliography. There the reader can easily find, directly or by way of an index, further sources or references pertinent to any topic mentioned in the text.

G.A. Pepin is a Research Officer in the MAFF Mycology Unit, Central Veterinary Laboratory, New Haw, Weybridge, Surrey KT15 3NB, UK. 